\title{
How to Keep Bathtub Water Temperture Comfortable over Time
}

\author{
Chang Cui \\ School of Environmental Science and Engineering, North China Electric Power \\ University, Baoding 071003, China \\ 872243977@qq.com
}

\begin{abstract}
In this paper, we established a model to discribe the how bathtub water temperature changed over time, and put forward a suitable way of adding hot water. We divided the bath process into three stages: cooling stage, heating up stage, and constant temperature stage. At the cooling stage and heating up stage, equations are selected according to the first law of thermodynamics. We analyzed the relations between the tub water temperature, injected water temperature and injection time. We used MATLAB to get the curves.
\end{abstract}

Keywords: Bathtub, Water Temperture, Model

\section{Process of bath}

The process of bathing can be divided into three stages:

- The first stage: the tub is filled with hot water and gets cool naturally.

- The second stage: Hot water is added once and for all to restore the temperature.

- The third stage: Hot water trickle is added from a faucet, constantly or once for all time, to maintain a comfortable temperature.

\section{Water temperature model}

\subsection{Assumptions:}

- The bathtub is filled with water during the whole bathing process.

- Environment temperature keeps constant.

- The shape/volume/temperature of the person in the bathtub keeps constant.

- Water temperature is uniform in the tub. 


\subsection{Parameters}

Table 1. Parameters of the model of bathtub water temperature

\begin{tabular}{ll}
\hline Parameter & Meaning \\
\hline$T$ & The water temperature in tub \\
$T_{S}$ & The initial water temperature in the cooling stage \\
$T_{C}$ & Temperature of outside environment \\
$k$ & Heat transfer coefficient \\
$A$ & Heat transfer surface area \\
$C$ & Specific heat capacity of water \\
$m$ & Mass of water in the tub \\
$\tau$ & Time \\
$\tau_{1}$ & Time length of the second stage \\
$q_{h}$ & Influent flow rate in the heating up stage \\
$T_{1}$ & Temperature of influent in the heating up stage \\
$T_{0}$ & Comfortable temperature/initial bathtub water temperature in the \\
$\Delta T$ & heating up stage \\
\hline
\end{tabular}

\section{Step1.}

In the cooling stage, the water is in natural cooling, so the average temperature of the water changes over time. Using heat transfer equation ${ }^{[1,2]}$.

$$
c m\left(T_{1}-T\right)=\int k A\left(T-T_{c}\right) d \tau ;
$$

The temperature of bathtub water:

$$
T=\left(T_{S}-T_{C}\right) e^{-\frac{k A}{c m}}+T_{C}
$$

Average water temperature in cooling stage decreases in a negative exponent form over time.

\section{Step2.}

In the heating up stage, the heat of bathtub water follows the first law of thermodynamics. The heat of water that added into the tub equals the heat of bathtub water delivered to enviroment.

1) Neglect the heat loss during adding process. Take the water temperature model of holothurian's aquaculture ${ }^{[3]}$ as reference:

$$
\tau_{1}=\frac{m}{q_{h}} \ln \frac{T_{S}-T_{1}}{T_{0}-T_{1}}
$$


The increase of temperature:

$$
T_{0}(\tau)=\frac{T_{0}-T_{1}+T_{1} e^{\frac{q_{h} \tau}{m}}}{e^{\frac{q_{h} \tau}{m}}}
$$

2) Consider the heat loss. Referring to the first law of thermodynamics:

$$
c m\left(T-T_{S}\right)=\int k A\left(T_{1}-T\right) d \tau ;
$$

Temperature of bathtub water:

$$
T=\left(T_{0}-T_{C}\right) e^{-\frac{k A}{c m} \tau}+T_{C}
$$

3) Combining the two conditions:

$$
T(\tau)=\frac{T_{0}-T_{1}+T_{1} e^{\frac{q_{h} \tau}{m}}}{e^{\frac{q_{h} \tau}{m}}}+\left(T_{0}-T_{C}\right) e^{-\frac{k A}{c m} \tau}+T_{C}-T_{S}
$$

\section{Step.3}

In the constant temperature stage, compare and analyse two ways of adding hot water.

Intermittent water adding: Add hot water to the tub by one time to achieve a higher temperature, when the bathtub water cools down, repeat the process.

Continuous water adding: After raising the water temperature in the heating stage, maintain a constant flow of hot water to keep the bathtub water temperature stable over time.

Assume these two methods provide the same level of comfort.

Water heat loss:

$$
q=c m \Delta T
$$

For both methods, the average water temperature of a certain period should be same. And the temperature of water being added into the bathtub is same, too. So the water consumption is in proportion to the heat loss.

For static water of same temperature, the heat loss is constant. But in the process of intermittent water adding, there exist some factors that can increase the heat loss, such as severe disturbance of water. So on the premise of ensuring a comfortable temperature, the later adding method uses less water.

Above all, in the third stage, we'd better to maintain a constant hot water flow. And water temperature in this stage will keep stable over time. 


\section{Numerical Computation and Results}

Assume that the bathtub is a cuboid. $(1.7 \mathrm{~m} \times 0.8 \mathrm{~m} \times 0.7 \mathrm{~m})$

Giving the following data:

Table 3. Parameters assignment

\begin{tabular}{ll}
\hline Parameter & Value \\
\hline$T_{S}$ & $40^{\circ} \mathrm{C}$ \\
$T_{C}$ & $20^{\circ} \mathrm{C}$ \\
$k$ & 200 \\
$A$ & $6.22 \mathrm{~m}^{2}$ \\
$C$ & $4.2 \mathrm{~kJ} /\left(\mathrm{kg} \cdot{ }^{\circ} \mathrm{C}\right)$ \\
$m$ & $952 \mathrm{~kg}$ \\
$T_{0}$ & $35^{\circ} \mathrm{C}$ \\
$T_{1}$ & $60^{\circ} \mathrm{C}$ \\
$q_{1}$ & $0.25 \mathrm{~kg} / \mathrm{s}$ \\
\hline
\end{tabular}

Bring the above data into formula (1) to (5).

The curve of the function:

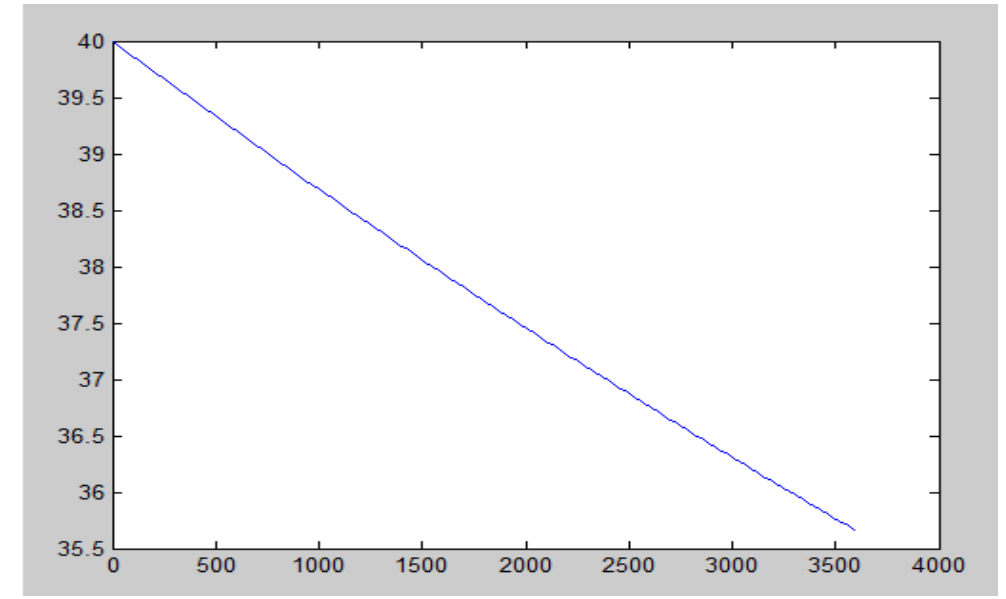

Figure 1. Water temperature over time in the cooling stage

The average temperature of water in this stage decreases in negative exponent form over time. 


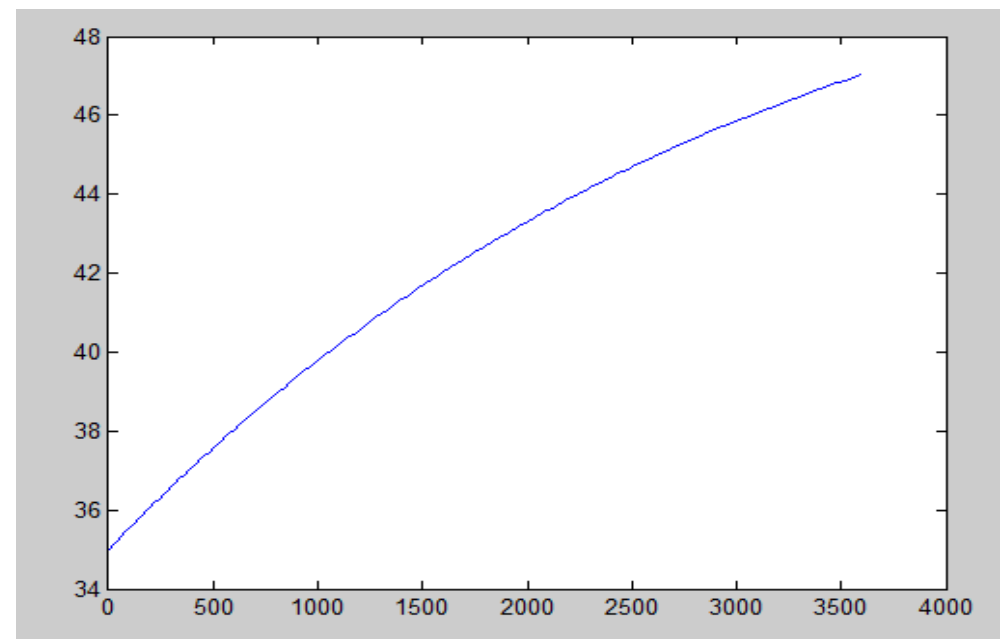

Figure 2. Water temperature over time in the heating up stage.

The average temperature of water in this stage decreases with the time continuing.

Water temperature over time in the third stage keeps stable.

\section{Conclusions}

We divide the bath process into three stages, and find that the better way to add hot water in the third stage is keeping a constant water flow. The average water temperature in the first stage decreases in a negative exponent form over time; the average water temperature in the second stage increases over time; the water temperature in the third stage, as we assumed, keeps constant, which demands a stable influent flow of $0.25 \mathrm{~kg} / \mathrm{s}$. However, this model only indicates a general trend of water temperature change during bathing process. The comfort temperature range of bathing depends on individual sensitivity, thus we only take a specific situation into consideration in the calculation.

\section{References}

[1] Pan Helin, Qi Ming zhai, Chen Xiao xiang. An Effective Deductive Method for Heat-Transfer Basic Equation. Higher Education in Chemical Engineering, 2008,(03):77-78.

[2] LI Cunsheng. Calculation of Water Beam Cooling in Heating Furnace. Industrial Furnace. Industrial Furnace, 2015, (03):55-57. 
[3] CHEN Zhi-hua, WANG Da-rui, LIU Qiu-juan. Design of water temperature control model in holothurian's aquaculture. Computer Engineering and Applications, 2007, 43( 32) : 225- 228. 